\title{
Paeoniflorin inhibits IL-1 $\beta$-induced expression of inflammatory mediators in human osteoarthritic chondrocyte
}

\author{
LIN ZHAO $^{1}$, QI CHANG $^{2}$, TAO HUANG ${ }^{2}$ and CHANGLIN HUANG ${ }^{3}$ \\ ${ }^{1}$ Department of Orthopedics; ${ }^{2}$ Institute of Military Training Related Medical Sciences, \\ The 150 Hospital of Chinese People's Liberation Army, Luoyang, Henan 471003; ${ }^{3}$ Institute of Orthopedics, \\ Xijing Hospital, Fourth Military Medical University, Xi'an, Shaanxi 710032, P.R. China
}

Received February 2, 2016; Accepted February 3, 2017

DOI: $10.3892 / \mathrm{mmr} .2017 .8222$

\begin{abstract}
Interleukin (IL)-1 $\beta$ serves an important role in the promotion of the growth of osteoarthritis (OA) lesions. Paeoniflorin (PF) has been identified to exert anti-inflammatory and anti-arthritic effects. However, it is uncertain whether PF may affect the expression levels of inflammatory mediators in OA chondrocytes. Therefore, the objective of the present study was to determine the effects of PF on the expression levels of inflammatory mediators in IL- $1 \beta$-stimulated human OA chondrocytes. The results of the present study determined that PF inhibited the production of nitric oxide and prostaglandin E2 induced by IL-1 $\beta$, and the expression of inducible nitric oxide synthase and cyclooxygenase- 2 in chondrocytes. Additionally, PF significantly inhibited the IL-1 $\beta$-stimulated production of metalloproteinase-3 (MMP-3) and MMP-13 in chondrocytes. $\mathrm{PF}$ inhibited the expression of nuclear factor- $\kappa \mathrm{B}(\mathrm{NF}-\kappa \mathrm{B}), \mathrm{p} 65$ and NF- $\kappa \mathrm{B}$ inhibitor $\alpha$ degradation was induced by IL- $1 \beta$ in chondrocytes. The results of the present study suggest that PF may inhibit IL-1 $\beta$-induced expression of inflammatory mediators in human OA chondrocytes by suppressing the activation of the NF- $\mathrm{NB}$ signaling pathway. Therefore, PF may be a potential agent in the future treatment of OA.
\end{abstract}

\section{Introduction}

Osteoarthritis (OA) is a degenerative disease of the joints that may lead to progressive cartilage damage, osteophyte formation and subchondral bone sclerosis, that may cause pain and loss of movement (1). OA affects $>50 \%$ of people over the age of 65 and is a highly debilitating disease (2). Although nonsteroidal anti-inflammatory drugs have been used clinically to treat OA, these agents ameliorate the clinical symptoms without suppressing the progression of the disease (3).

Correspondence to: Dr Changlin Huang, Institute of Orthopedics, Xijing Hospital, Fourth Military Medical University, 17 Changle West Road, Xi'an, Shaanxi 710032, P.R. China

E-mail: changlinxj@163.com

Key words: inflammatory mediators, paeoniflorin, osteoarthritis, chondrocytes
Therefore, investigation of safer and better tolerated agents for the treatment of OA is required.

Previous studies have revealed that pro-inflammatory cytokines, including interleukin (IL)-1 $\beta$, serve a critical role in the pathogenesis of OA (4-6). In response to IL-1 $\beta$ upregulation, chondrocytes secrete matrix metalloproteinases (MMPs), which induce chondrocyte apoptosis and inhibit extracellular matrix (ECM) biosynthesis (7). IL-1 $\beta$ also induced the expression of cyclooxygenase-2 (COX-2) and inducible nitric oxide synthase (iNOS) (8), which may lead to the elevated production of prostaglandin E2 (PGE2) and nitric oxide (NO), respectively.

Paeoniflorin (PF) is a monoterpene glycoside extracted from the root of Paeonia lactiflora Pall. Previous studies have indicated that $\mathrm{PF}$ has a protective effect on various pathological states, including tumor growth, oxidative stress, inflammation, and myocardial infarction (9-12). Liu et al (13) reported that $\mathrm{PF}$ pretreatment inhibited amyloid $\beta 1-42$-induced production of tumor necrosis factor $\alpha, \mathrm{IL}-1 \beta$ and IL- 6 in rodent microglia. Additionally, $\mathrm{PF}$ exhibits an anti-arthritic effect. It was reported that $\mathrm{PF}$ reduced the levels of inflammatory cytokines and alleviated rheumatoid arthritis in collagen-induced arthritis (14). However, it remains to be elucidated whether PF affects inflammatory responses in OA chondrocytes. Therefore, the objective of the present study was to investigate the effects of $\mathrm{PF}$ on inflammatory responses in OA chondrocytes.

\section{Materials and methods}

Tissue collection and human articular chondrocytes culture. Osteoarthritis cartilage tissues were obtained from 10 patients (all female; age, $63 \pm 5$ years) with OA that underwent total knee joint replacement between July and December 2014, at the Affiliated Hospital of Shandong University (Jinan, China). The present study was performed following a protocol approved by Medical Ethical Committee of the Institute of Orthopedics, Xijing Hospital, Fourth Military Medical University (Xi'an, China) and all examinations were performed after written informed consent was obtained from the patients.

Chondrocytes were isolated from cartilage as previously described (15). The whole articular cartilage was minced into pieces $\sim 0.5 \mathrm{~cm}^{2}$. Following enzymatic digestion with $2 \mathrm{mg} / \mathrm{ml}$ pronase in serum-free Dulbecco's modified Eagle's medium (DMEM; Invitrogen; Thermo Fisher Scientific, Inc., Waltham, 
MA, USA) containing $100 \mathrm{U} / \mathrm{ml}$ penicillin and $100 \mu \mathrm{g} / \mathrm{ml}$ streptomycin (Sigma-Aldrich; Merck KGaA, Darmstadt, Germany) for $2 \mathrm{~h}$ at $37^{\circ} \mathrm{C}$ in $5 \% \mathrm{CO}_{2}$ atmosphere, the specimens were then digested with $0.2 \%(\mathrm{v} / \mathrm{v})$ collagenase I for $4 \mathrm{~h}$ at $37^{\circ} \mathrm{C}$. Primary chondrocytes were cultured at a density of $1 \times 10^{5}$ cells $/ \mathrm{ml}$ in petri dishes in monolayer culture for a period of $24 \mathrm{~h}$ at $37^{\circ} \mathrm{C}$ with $5 \% \mathrm{CO}_{2}$, and chondrocytes in passages 5 to 9 were used.

Cell viability. Cell viability was quantified by a Cell Counting Kit-8 assay (CCK-8; Dojindo Molecular Technologies, Inc., Kumamoto, Japan). Human chondrocytes $\left(1 \times 10^{4}\right.$ cells/well $)$ in 96-well plates were pretreated with 10,50 and $100 \mu \mathrm{g} / \mathrm{ml}$ $\mathrm{PF}$ (Sigma-Aldrich; Merck KGaA) for $2 \mathrm{~h}$ at $37^{\circ} \mathrm{C}$ and subsequently co-incubated in the absence or presence of $10 \mathrm{ng} / \mathrm{ml}$ IL-1 $\beta$ (Sigma-Aldrich; Merck KGaA) at room temperature for $24 \mathrm{~h}$. Then, CCK-8 reagents were added and incubated with the cells for $1 \mathrm{~h}$ at $37^{\circ} \mathrm{C}$. The spectrophotometric absorbance was quantified at $490 \mathrm{~nm}$ on a multifunctional microplate reader (Tecan Group Ltd., Durham, NC, USA).

Nitric oxide (NO) and prostaglandin E2 (PGE2) quantification . NO levels in the culture medium were detected by Griess reaction, as previously described (16). PGE2 levels were investigated using a commercially available ELISA kit, according to the manufacturer's protocol (KHL1701; Invitrogen; Thermo Fisher Scientific, Inc.).

Reverse transcription-quantitative polymerase chain reaction $(R T-q P C R)$. Total RNA was isolated from human chondrocytes using TRIzol (Invitrogen; Thermo Fisher Scientific, Inc.), according to the manufacturer's protocol. Total RNA $(5 \mu \mathrm{g})$ for each sample were reverse transcribed into first strand cDNA using the iScript cDNA synthesis kit (Bio-Rad Laboratories, Inc., Hercules, CA, USA) according to manufacturer's protocol for subsequent qPCR analysis. qPCR was performed in a final volume of $10 \mu \mathrm{l}$, which contained $5 \mu \mathrm{l}$ of SsoFast ${ }^{\mathrm{TM}}$ EvaGreen Supermix (Bio-Rad Laboratories, Inc.), $1 \mu \mathrm{l}$ of cDNA (1:50 dilution) and $2 \mu \mathrm{l}$ of the forward and reverse primers $(1 \mathrm{mM})$. The following specific primer sequences were used: iNOS, sense 5'-TTTCCAAGACACACTTCACCA-3', antisense 5'-ATCTCCTTTGTTACCGCTTCC-3'; sense COX-2 5'-GAGAGATGTATCCTCCCACAGTCA-3', antisense 5'-GACCAGGCACCAGACCAAAG-3'; and for $\beta$-actin, sense 5'-AGAAGGCTGGGGCTCATTTG-3', antisense 5'-AGGGGCCATCCACAGTCTTC-3'. Thermocycling conditions were as follows: $94^{\circ} \mathrm{C}$ for $5 \mathrm{~min}$; subsequently 35 cycles at $94^{\circ} \mathrm{C}$ for $1 \mathrm{~min}, 59^{\circ} \mathrm{C}$ for $15 \mathrm{sec}$ and $72^{\circ} \mathrm{C}$ for $30 \mathrm{sec}$; followed by $72^{\circ} \mathrm{C}$ for $10 \mathrm{~min}$. qPCR data was calculated by the $2^{-\Delta \Delta \mathrm{Cq}}$ method (17).

Western blotting. Chondrocytes were washed twice with ice-cold PBS and sonicated with lysis buffer (Takara Biotechnology Co., Ltd., Dalian, China), the cell lysate supernatants were harvested by centrifugation at $10,000 \times g$ for $10 \mathrm{~min}$ at $4^{\circ} \mathrm{C}$. The protein concentrations of the cell supernatants were then quantified using Bradford protein dye reagent (Bio-Rad Laboratories). Proteins (30 $\mu \mathrm{g} / \mathrm{lane})$ were separated by $12 \%$ SDS-PAGE and transferred onto polyvinylidene difluoride membranes (EMD Millipore, Boston, MA, USA). The membranes were incubated with

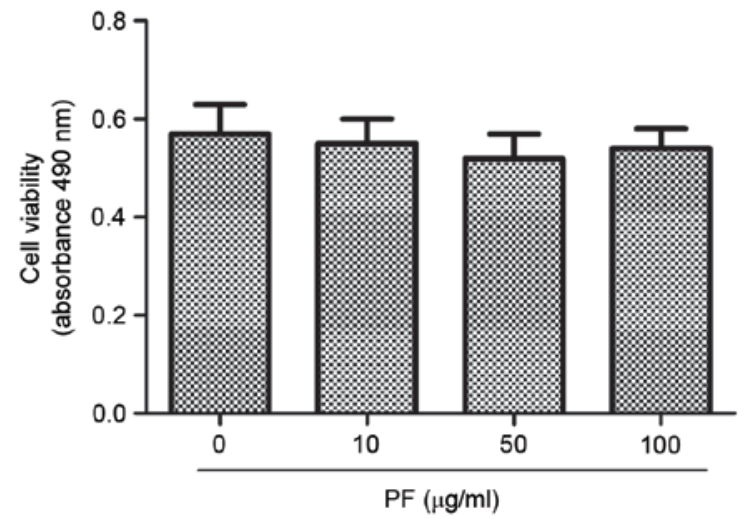

Figure 1. Effects of PF on cell viability in human osteoarthritis chondrocytes. Chondrocytes at a density of $1 \times 10^{4}$ cells/well were pretreated with 10,50 or $100 \mu \mathrm{g} / \mathrm{ml} \mathrm{PF}$ for $24 \mathrm{~h}$ and a Cell Counting Kit-8 assay was used to evaluate cell viability. At least three independent experiments were performed. PF, paeoniflorin.

A

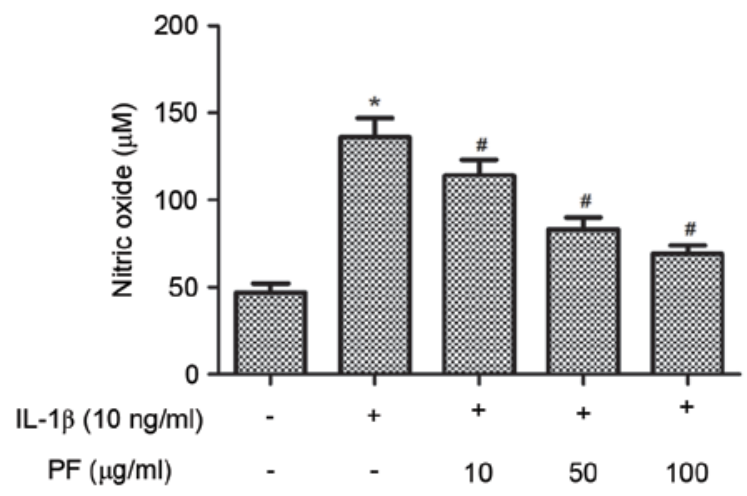

B

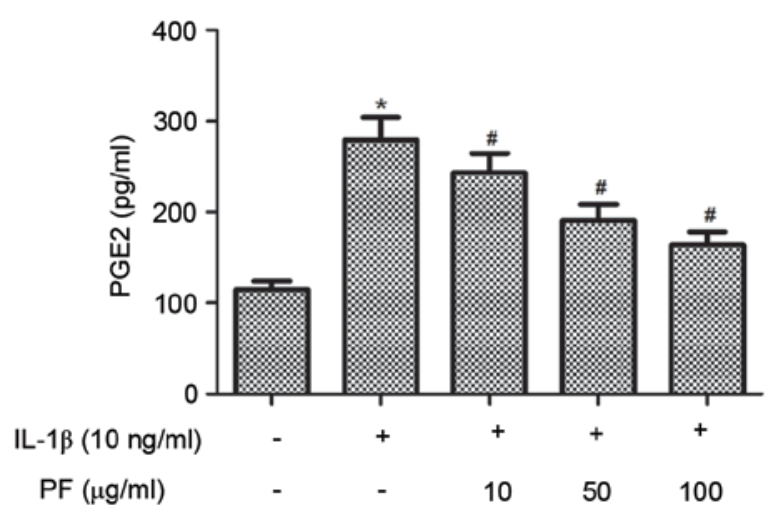

Figure 2. PF inhibits the production of nitric oxide and PGE2 in IL-1 $\beta$-stimulated osteoarthritis chondrocytes. Chondrocytes at a density of $1 \times 10^{5}$ cells/well were pretreated with 10,50 or $100 \mu \mathrm{g} / \mathrm{ml} \mathrm{PF} 2 \mathrm{~h}$ prior to $10 \mathrm{ng} / \mathrm{ml} \mathrm{IL}-1 \beta$ for $24 \mathrm{~h}$. (A) Nitric oxide levels in the culture medium were assessed by Griess reaction. (B) PGE2 levels were determined using a commercial ELISA kit. At least three independent experiments were performed. ${ }^{*} \mathrm{P}<0.05$ vs. control; ${ }^{\#} \mathrm{P}<0.05$ vs. IL-1 $\beta$. PF, paeoniflorin; IL-1 $\beta$, interleukin 1 $\beta$; PGE2, prostaglandin E2.

appropriate primary antibodies for iNOS (1:2,000; sc-7271), COX-2 (1:3,000; sc-19,999), nuclear factor (NF)-кB p65 
A

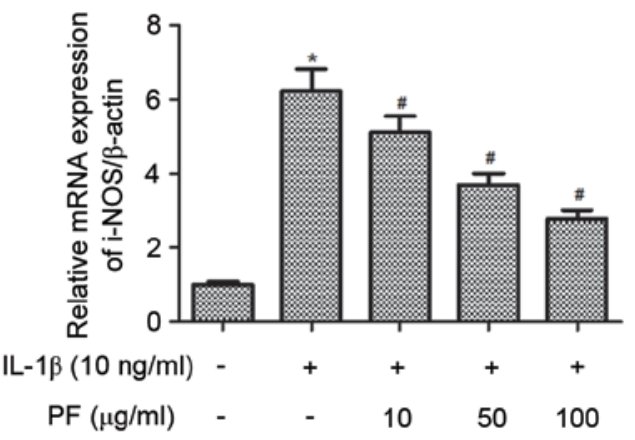

B

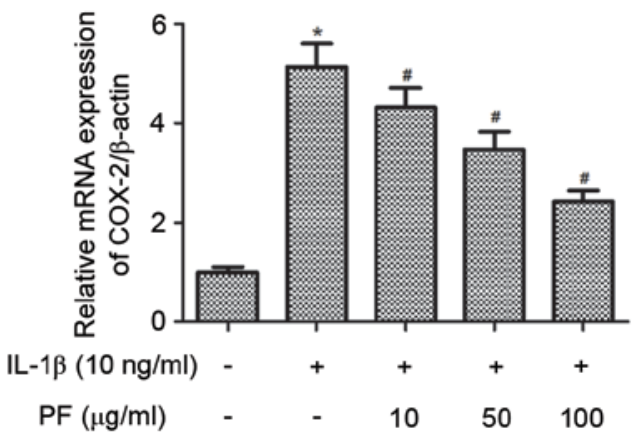

C

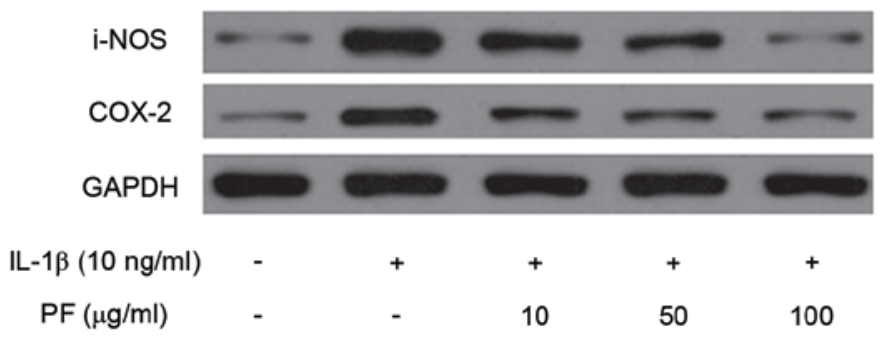

D

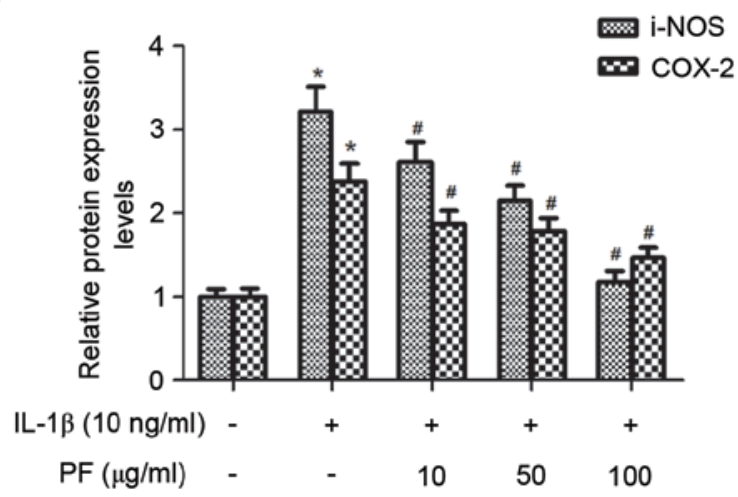

Figure 3. PF inhibits the expression of iNOS and COX-2 in IL-1 $\beta$-stimulated osteoarthritis chondrocytes. Chondrocytes at a density of $1 \times 10^{5}$ cells/well were pretreated with 10,50 or $100 \mu \mathrm{g} / \mathrm{ml} \mathrm{PF}$ for $2 \mathrm{~h}$ prior to $10 \mathrm{ng} / \mathrm{ml} \mathrm{IL-1 \beta}$ for $24 \mathrm{~h}$. RT-qPCR analysis of (A) iNOS and (B) COX-2 in chondrocytes. Gene expression was normalized to $\beta$-actin. (C) Western blot analysis of iNOS and COX-2 in chondrocytes. (D) Relative protein expression levels of iNOS and COX-2 were quantified using BandScan 5.0 software and normalized to GAPDH. At least three independent experiments were performed. "P<0.05 vs. control; " $\mathrm{P}<0.05$

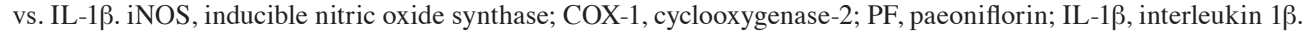

$(1: 1,500 ; \mathrm{sc}-8008)$, inhibitor of $\kappa \mathrm{B}(\mathrm{I} \kappa \mathrm{B} \alpha)(1: 3,000 ; \mathrm{sc}-1643)$ and GAPDH (1:3,000; sc-59540) (Santa Cruz Biotechnology, Inc., Dallas, TX, USA) overnight at $4^{\circ} \mathrm{C}$. The membranes were subsequently washed with PBS containing $0.1 \%(\mathrm{v} / \mathrm{v})$ Tween 20 and incubated with horseradish peroxidase-conjugated secondary antibodies (1:2,500; sc-2005; Santa Cruz Biotechnology, Inc.) for $1 \mathrm{~h}$ at room temperature, followed by exposure using enhanced chemiluminescence detection reagents (Gibco; Thermo Fisher Scientific, Inc.). BandScan version 5.0 (Glyko, Inc., Novato, CA, USA) was used for the quantification of all the proteins following western blot analysis.
Enzyme-linked immunosorbent assay (ELISA). Culture medium was collected for ELISA assay. MMP-3 and MMP-13 levels were quantified using ELISA kits for human MMP3 and MMP13 (KAC1541 and EHMMP13; both from Invitrogen; Thermo Fisher Scientific, Inc.), according to the manufacturer's protocol.

Statistical analysis. The quantitative data are expressed as the mean \pm standard deviation. Statistical significance was assessed by the one-way analysis of variance followed by Tukey's post hoc test. $\mathrm{P}<0.05$ was considered to indicate a statistically significant difference. 
A

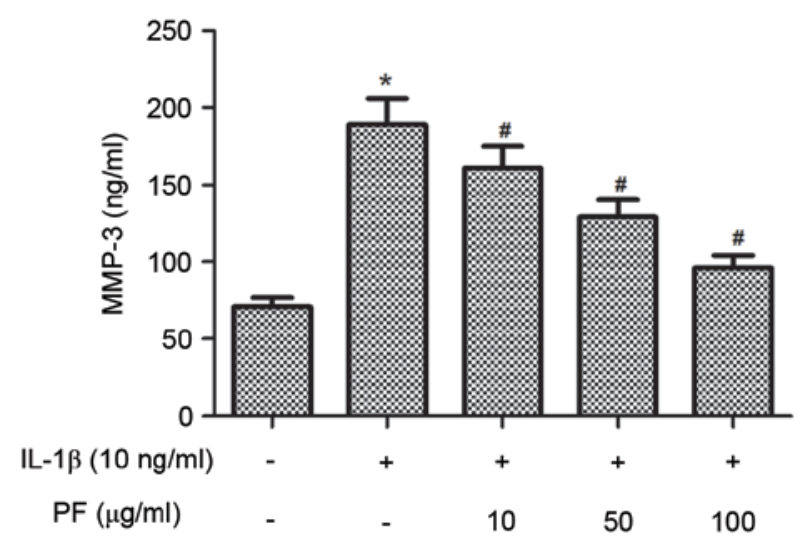

B

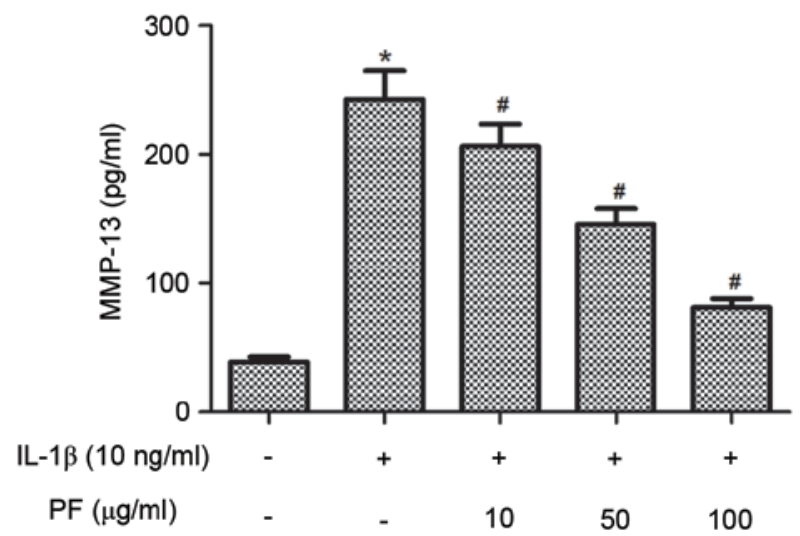

Figure 4. PF inhibits the production of MMP-3 and MMP-13 in IL-1 $\beta$-stimulated osteoarthritis chondrocytes. Chondrocytes at a density of $1 \times 10^{5}$ cells/well were pretreated with 10,50 or $100 \mu \mathrm{g} / \mathrm{ml} \mathrm{PF} 2 \mathrm{~h}$ prior to $10 \mathrm{ng} / \mathrm{ml} \mathrm{IL}-1 \beta$ for $24 \mathrm{~h}$. ELISA was performed to determine the production of (A) MMP-3 and (B) MMP-13 in chondrocytes. At least three independent experiments were performed. ${ }^{*} \mathrm{P}<0.05$ vs. control; ${ }^{~} \mathrm{P}<0.05$ vs. IL-1 $\beta$. MMP, metalloproteinase; PF, paeoniflorin; IL-1 $\beta$, interleukin $1 \beta$.

\section{Results}

Effect of PF on viability of human OA chondrocytes. Human OA chondrocytes were incubated with $0,10,50$ and $100 \mu \mathrm{g} / \mathrm{ml}$ $\mathrm{PF}$ for $24 \mathrm{~h}$, and the cell viability was determined using a CCK-8 assay (Fig. 1). At concentrations of 10, 50 and $100 \mu \mathrm{g} / \mathrm{ml}, \mathrm{PF}$ induced no cytotoxic effects in human OA chondrocytes.

Effect of PF on NO and PGE2 production in IL-1 $\beta$-stimulated chondrocytes. Subsequently the effects of PF on NO and PGE2 production in IL-1 $\beta$-stimulated human OA chondrocytes were investigated. As indicated in Fig. 2, IL-1 $\beta$ significantly increased the production of NO and PGE2 compared with the control group $(\mathrm{P}<0.05)$. However, treatment with $\mathrm{PF}$ significantly inhibited NO and PGE2 production induced by IL-1 $\beta$ in human OA chondrocytes $(\mathrm{P}<0.05)$.

Effect of PF on iNOS and COX-2 expression levels in IL-1 $\beta$-stimulated chondrocytes. The effect of PF on
A

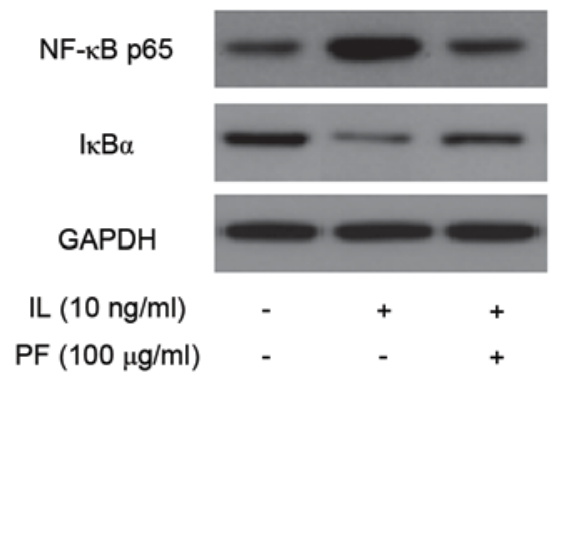

B

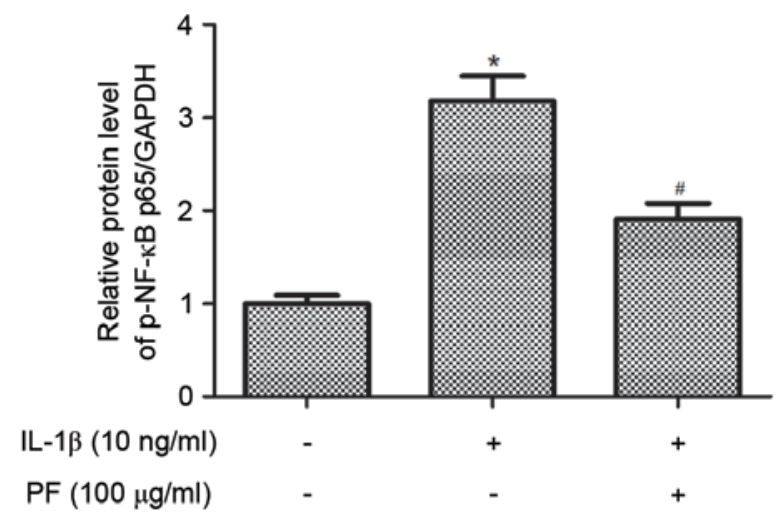

C

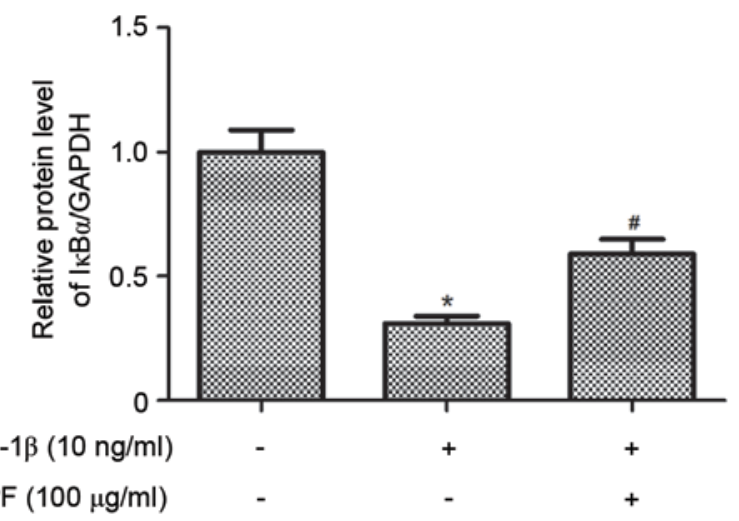

Figure 5. PF inhibits NF- $\mathrm{kB}$ activation in IL-1 $\beta$-stimulated chondrocytes. Chondrocytes at a density of $1 \times 10^{5}$ cells/well were pretreated with PF for $24 \mathrm{~h}$ and then stimulated with $10 \mathrm{ng} / \mathrm{ml} \mathrm{IL-1 \beta}$ for $1 \mathrm{~h}$. (A) The protein levels

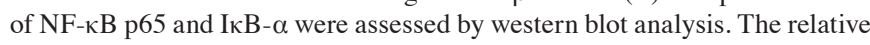

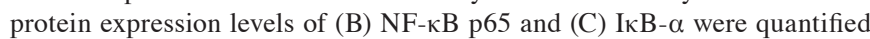
using BandScan 5.0 software and normalized to GAPDH. At least three independent experiments were performed. ${ }^{*} \mathrm{P}<0.05$ vs. control; ${ }^{\#} \mathrm{P}<0.05$ vs. IL- $1 \beta$. $\mathrm{NF}-\kappa \mathrm{B}$, nuclear factor $\kappa \mathrm{B}$; IкB- $\alpha$, inhibitor of $\kappa \mathrm{B}$; PF, paeoniflorin; IL-1 $\beta$, interleukin $1 \beta$.

iNOS and COX-2 mRNA and protein expression levels in IL-1 $\beta$-induced chondrocytes were evaluated by RT-qPCR and western blot analysis. As presented in Fig. 3A and B, IL-1 $\beta$ treatment significantly increased the mRNA expression levels of iNOS and COX-2 ( $\mathrm{P}<0.05)$ compared with the control. However, 
treatment with PF significantly inhibited IL-1 $\beta$-induced expression of iNOS and COX-2 in chondrocytes $(\mathrm{P}<0.05)$. Western blot analysis demonstrated that $\mathrm{PF}$ also inhibited the protein expression levels of iNOS and COX-2 induced by IL- $1 \beta$ in human OA chondrocytes ( $\mathrm{P}<0.05$; Fig. $3 \mathrm{C}$ and D).

Effect of PF on production of MMPs in IL-1 $\beta$-stimulated chondrocytes. It is established that MMPs perform a critical role in bone remodeling and OA; therefore, the present study investigated the effect of PF on MMP-3 and MMP-13 production in IL-1 $\beta$-induced chondrocytes. As presented in Fig. 4, chondrocytes stimulated with IL-1 $\beta$ exhibited significantly increased levels of MMP-3 and MMP-13 compared with the control group $(\mathrm{P}<0.05)$. However, treatment of chondrocytes with PF significantly reduced the production of MMP-3 and MMP-13 induced by IL-1 $\beta$ in human OA chondrocytes $(\mathrm{P}<0.05)$.

Effect of PF on NF- $\kappa B$ activation in IL-1 $\beta$-stimulated chondrocytes. In order to further understand the anti-inflammatory mechanisms of $\mathrm{PF}$, the present study examined the level of NF- $\kappa \mathrm{B}$ p65 expression in IL-1 $\beta$-stimulated chondrocytes. As indicated in Fig. 5, the protein expression level of $\mathrm{NF}-\kappa \mathrm{B}$ p65 in the nucleus of chondrocytes was significantly increased by IL-1 $\beta$ compared with the untreated control $(\mathrm{P}<0.05)$. However, $\mathrm{PF}$ significantly suppressed the expression

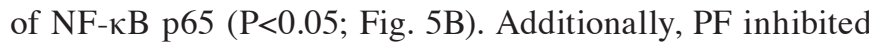
IL-1 $\beta$-induced I $\kappa \mathrm{B}-\alpha$ degradation in human OA chondrocytes $(\mathrm{P}<0.05$; Fig. 5C).

\section{Discussion}

Inflammatory cytokines serve important roles in the pathogenesis of OA. The results of the present study indicate that pretreatment with PF inhibited the production of NO and PGE2 induced by IL-1 $\beta$, and the expression of iNOS and COX-2 in chondrocytes. Pretreatment with PF also significantly inhibited the IL-1 $\beta$-stimulated production of MMP-3 and MMP-13 in chondrocytes. Furthermore, PF inhibited the expression of $\mathrm{NF}-\kappa \mathrm{B}$ p 65 and $\mathrm{I} \kappa \mathrm{B}-\alpha$ degradation induced by IL- $1 \beta$ in OA chondrocytes.

NO is an inflammatory mediator, which is produced by iNOS. PGE2 is also an inflammatory factor, which is elevated by COX-2. Increased serum levels of NO and PGE2 have been previously observed in patients with OA $(18,19)$. Additionally, IL-1 $\beta$ has been identified as a potent inducer of iNOS and COX-2 in cultured chondrocytes in vitro (8). The present study determined that PF inhibited the production of NO and PGE2 induced by IL-1 $\beta$ and the expression of iNOS and COX-2 in chondrocytes. These results are supported by Guo et al (20), that determined treatment with $\mathrm{PF}$ reduced the protein expression levels of iNOS and COX2 and 5-lipoxidase in the brain of transient middle cerebral artery occlusion rats (20). The results of the present study suggest that the inhibition of NO and PGE2 by PF may be associated with the regulation of the expression levels of iNOS and COX-2 in chondrocytes.

Previous studies indicated that an excess of MMPs may have an important role in the progression of OA, as they are proteolytic enzymes, in OA progression they may be associated with their ability to degrade the ECM (20-23). MMP-3 and
MMP-13 are important for degrading collagens, proteoglycans and other ECM macromolecules in chondrocytes. MMP-3 may aggravate inflammation via the activation of various pro-MMPs and cleaves extracellular components (24). MMP-13 may also degrade the ECM, including the cartilage-specific component type II collagen during the progression of OA (25). The present study determined that PF may inhibit IL-1 $\beta$-induced production of MMP-3 and MMP-13 in human OA chondrocytes. Therefore, the results of the present study revealed that PF exerted an anti-arthritic effect via inhibition of the MMP-3 and MMP-13 expression levels.

Among multiple pathways and mediators influencing the development of $\mathrm{OA}, \mathrm{NF}-\kappa \mathrm{B}$ transcription factor has a prominent role $(16,26,27)$. It has been reported that IL- $1 \beta$ may activate $\mathrm{NF}-\kappa \mathrm{B}$ via triggering of $\mathrm{I} \kappa \mathrm{B} \alpha$ degradation, leading to the translocation of $\mathrm{NF}-\kappa \mathrm{B}$ p65 from cytoplasm to nucleus to regulate the expression of various inflammation-associated genes (28). Additionally, it was previously reported that $\mathrm{NF}-\kappa \mathrm{B}$ may stimulate the expression level of enzymes, such as iNOS and COX-2 in chondrocytes and the products of these enzymes may contribute to the pathogenesis of OA (29). The $\mathrm{NF}-\kappa \mathrm{B}$ inhibitor has been identified to reduce IL-1 $\beta$-induced MMP-3 and MMP-13 production in human chondrocytes (30). The present study determined that PF inhibited the expression of NF- $\kappa$ B p65 and I $\kappa$ B- $\alpha$ degradation induced by IL-1 $\beta$ in chondrocytes. The results of the current study are partly supported by Wu et al (31), that determined that PF may suppress $\mathrm{NF}-\kappa \mathrm{B}$ activation through modulation of $\mathrm{I} \kappa \mathrm{B}-\alpha$ in human gastric carcinoma cells. In a recent study, PF was also identified to block nuclear translocation of NF- $\kappa$ B p 65 in lipopolysaccharide-stimulated RAW264.7 mouse macrophage cells (32). These previous results combined with the present study suggest that PF may inhibit IL-1 $\beta$-induced expression of inflammatory mediators by suppressing the activation of the NF- $\kappa \mathrm{B}$ signaling pathway in human OA chondrocytes.

In conclusion, the results of the present study suggest that PF may inhibit the expression of inflammatory mediators in IL-1 $\beta$-induced OA chondrocytes by suppressing the activation of the NF- $\kappa \mathrm{B}$ signaling pathway. Therefore, PF may be a potential therapeutic agent for the future treatment of OA.

\section{References}

1. Buckwalter JA, Mankin HJ and Grodzinsky AJ: Articular cartilage and osteoarthritis. Instr Course Lect 54: 465-480, 2005.

2. Jakobsson U and Hallberg IR: Pain and quality of life among older people with rheumatoid arthritis and/or osteoarthritis: A literature review. J Clin Nurs 11: 430-443, 2002.

3. Richette P, Latourte A and Frazier A: Safety and efficacy of paracetamol and NSAIDs in osteoarthritis: Which drug to recommend? Expert Opin Drug Saf 14: 1259-1268, 2015.

4. Loeser RF: Molecular mechanisms of cartilage destruction: Mechanics, inflammatory mediators, and aging collide. Arthritis Rheum 54: 1357-1360, 2006.

5. Zhou PH, Liu SQ and Peng H: The effect of hyaluronic acid on IL-1beta-induced chondrocyte apoptosis in a rat model of osteoarthritis. J Orthop Res 26: 1643-1648, 2008.

6. Goldring SR and Goldring MB: The role of cytokines in cartilage matrix degeneration in osteoarthritis. Clin Orthop Relat (427 Suppl): S27-S36, 2004.

7. Mengshol JA, Vincenti MP, Coon CI, Barchowsky A and Brinckerhoff CE: Interleukin-1 induction of collagenase 3 (matrix metalloproteinase 13) gene expression in chondrocytes requires p38, c-jun $\mathrm{N}$-terminal kinase and nuclear factor kappaB: Differential regulation of collagenase 1 and collagenase 3 . Arthritis Rheum 43: 801-811, 2000. 
8. Chabane N, Zayed N, Afif H, Mfuna-Endam L, Benderdour M, Boileau C, Martel-Pelletier J, Pelletier JP, Duval N and Fahmi H: Histone deacetylase inhibitors suppress interleukin-1beta-induced nitric oxide and prostaglandin E2 production in human chondrocytes. Osteoarthritis Cartilage 16: 1267-1274, 2008

9. Wang H, Zhou H, Wang CX, Li YS, Xie HY, Luo JD and Zhou Y: Paeoniflorin inhibits growth of human colorectal carcinoma HT 29 cells in vitro and in vivo. Food Chem Toxicol 50: 1560-1567, 2012.

10. Wankun X, Wenzhen Y, Min Z, Weiyan Z, Huan C, Wei D, Lvzhen $\mathrm{H}, \mathrm{Xu} \mathrm{Y}$ and Xiaoxin L: Protective effect of paeoniflorin against oxidative stress in human retinal pigment epithelium in vitro. Mol Vis 17: 3512-3522, 2011.

11. Cao W, Zhang W, Liu J, Wang Y, Peng X, Lu D, Qi R, Wang Y and Wang H: Paeoniflorin improves survival in LPS-challenged mice through the suppression of TNF- $\alpha$ and IL-1 $\beta$ release and augmentation of IL-10 production. Int Immunopharmacol 11: 172-178, 2011.

12. Nizamutdinova IT, Jin YC, Kim JS, Yean MH, Kang SS, Kim YS, Lee JH, Seo HG, Kim HJ and Chang KC: Paeonol and paeoniflorin, the main active principles of Paeonia albiflora, protect the heart from myocardial ischemia/reperfusion injury in rats. Planta Med 74: 14-18, 2008.

13. Liu H, Wang J, Wang J, Wang P and Xue Y: Paeoniflorin attenuates $A \beta 1-42$-induced inflammation and chemotaxis of microglia in vitro and inhibits NF- $\kappa \mathrm{B}$ - and VEGF/Flt-1 signaling pathways. Brain Res 1618: 149-158, 2015.

14. Wu D, Chen J, Zhu H, Xiong XG, Liang OH, Zhang Y, Zhang Y, Wang Y, Yang B and Huang X: UPLC-PDA determination of paeoniflorin in rat plasma following the oral administration of Radix Paeoniae Alba and its effects on rats with collagen-induced arthritis. Exp Ther Med 7: 209-217, 2014.

15. Cheng AW, Stabler TV, Bolognesi M and Kraus VB: Selenomethionine inhibits IL- $1 \beta$ inducible nitric oxide synthase (iNOS) and cyclooxygenase 2 (COX2) expression in primary human chondrocytes. Osteoarthritis Cartilage 19: 118-125, 2011.

16. Marcu KB, Otero M, Olivotto E, Borzí RM and Goldring MB NF-kappaB signaling: Multiple angles to target OA. Curr Drug Targets 11: 599-613, 2010.

17. Livak KJ and Schmittgen TD: Analysis of relative gene expression data using real-time quantitative PCR and the 2(-Delta Delta C(T)) method. Methods 25: 402-408, 2001.

18. Salvatierra J, Escames G, Hernandez P, Cantero J, Crespo E, Leon J, Salvatierra D, Acuña-Castroviejo D and Vives F: Cartilage and serum levels of nitric oxide in patients with hip osteoarthritis. J Rheumatol 26: 2015-2017, 1999.

19. Salvemini D, Misko TP, Masferrer JL, Seibert K, Currie MG and Needleman P: Nitric oxide activates cyclooxygenase enzymes. Proc Natl Acad Sci USA 90: 7240-7244, 1993.
20. Guo RB, Wang GF, Zhao AP, Gu J, Sun XL and Hu G: Paeoniflorin protects against ischemia-induced brain damages in rats via inhibiting MAPKs/NF- $\mathrm{KB}$-mediated inflammatory responses. PLoS One 7: e49701, 2012.

21. Tetlow LC, Adlam DJ and Woolley DE: Matrix metalloproteinase and proinflammatory cytokine production by chondrocytes of human osteoarthritic cartilage: Associations with degenerative changes. Arthritis Rheum 44: 585-594, 2001.

22. Dean DD, Martel-Pelletier J, Pelletier JP, Howell DS and Woessner JF Jr: Evidence for metalloproteinase and metalloproteinase inhibitor imbalance in human osteoarthritic cartilage. J Clin Invest 84: 678-685, 1989.

23. Mahmoud RK, El-Ansary AK, El-Eishi HH, Kamal HM and El-Saeed NH: Matrix metalloproteinases MMP-3 and MMP-1 levels in sera and synovial fluids in patients with rheumatoid arthritis and osteoarthritis. Ital J Biochem 54: 248-257, 2005.

24. Wu JJ, Lark MW, Chun LE and Eyre DR: Sites of stromelysin cleavage in collagen types II, IX, X, and XI of cartilage. J Biol Chem 266: 5625-5628, 1991.

25. Aigner T, Fundel K, Saas J, Gebhard PM, Haag J, Weiss T, Zien A, Obermayr F, Zimmer R and Bartnik E: Large-scale gene expression profiling reveals major pathogenetic pathways of cartilage degeneration in osteoarthritis. Arthritis Rheum 54: 3533-3544, 2006

26. Scanzello CR and Goldring SR: The role of synovitis in osteoarthritis pathogenesis. Bone 51: 249-257, 2012.

27. Roman-Blas JA and Jimenez SA: NF-kappaB as a potential therapeutic target in osteoarthritis and rheumatoid arthritis. Osteoarthritis Cartilage 14: 839-848, 2006.

28. Newton R, Kuitert LM, Bergmann M, Adcock IM and Barnes PJ: Evidence for involvement of NF-kappaB in the transcriptional control of COX-2 gene expression by IL-1beta. Biochem Biophys Res Commun 237: 28-32, 1997.

29. Stuhlmeier KM: The anti-rheumatic gold salt aurothiomalate suppresses interleukin-1beta-induced hyaluronan accumulation by blocking HAS1 transcription and by acting as a COX-2 transcriptional repressor. J Biol Chem 282: 2250-2258, 2007.

30. Liacini A, Sylvester J, Li WQ and Zafarullah M: Inhibition of interleukin-1-stimulated MAP kinases, activating protein-1 (AP-1) and nuclear factor kappa B (NF-kappaB) transcription factors down-regulates matrix metalloproteinase gene expression in articular chondrocytes. Matrix Biol 21: 251-262, 2002

31. Wu H, Li W, Wang T, Shu Y and Liu P: Paeoniflorin suppress NF-kappaB activation through modulation of IkappaB alpha and enhances 5-fluorouracil-induced apoptosis in human gastric carcinoma cells. Biomed Pharmacother 62: 659-666, 2008.

32. Zhang J, Dou W, Zhang E, Sun A, Ding L, Wei X, Chou G, Mani S and Wang Z: Paeoniflorin abrogates DSS-induced colitis via a TLR4-dependent pathway. Am J Physiol Gastrointest Liver Physiol 306: G27-G36, 2014. 